\title{
Commentary: The Ever-Changing Brain
}

Bruce S. McEwen, Ph.D.

Ramón y Cajal is quoted as stating that the adult brain is structurally stable and cannot be changed or repaired. Whether or not Ramón y Cajal should take the sole blame for this notion, it has certainly been a longheld belief in neuroscience. But things have changed radically in recent years and neurogenesis, the topic of this series of 3 articles, is only part of the story and yet a very important and exciting one.

Before discussing neurogenesis, it is worthwhile to briefly note some of the ways in which the adult brain has been found to be capable of adaptive structural changes. Among the first studies of this kind were those on the so-called enriched environment, that revealed, in young adult as well as aging rats, growth of cortical neuronal processes and glial cell proliferation in response to a living environment that contained toys and interesting new things as opposed to a typical rat cage environment (Bennett et al. 1964; Diamond and Connor 1982; Black et al. 1989). Another type of structural plasticity that challenged the notion of a static brain is the work that documented collateral sprouting of neurons after lesions in the entorhinal cortex: e.g., (Parnavelas et al. 1974). More recently, the structural reorganization of the thalamocortical connections after limb deafferentation have also been recognized (Jones and Pons 1998; Florence et al. 1998).

Yet, as indicated in the enriched environment studies, the non-damaged brain is capable of considerable structural plasticity and changes, for example, under the influence of patterned stimulation of auditory or tactile input: e.g., (Kilgard and Merzenich 1998; Wang

Address correspondence to: Dr. B. McEwen, Rockefeller University, 1230 York Ave., Box 165, New York, NY 10021, Tel.: (212) 3278624, Fax: (212) 327-8634, E-mail: mcewen@rockvax.rockefeller.edu et al. 1995). Circulating hormones also play a significant role in structural remodeling of the undamaged adult brain, as exemplified by androgen induced synaptic remodeling of the spinal cord (Rand and Breedlove 1995), ovarian hormone-induced synapse turnover in hippocampus (Yankova et al. 2001), and stress-induced remodeling of dendrites in hippocampus (Magarinos et al. 1996). Even some sex specific changes in neuronal structure and connectivity may be the product of hormone actions in adult life, rather than solely due to early developmental influences (Cooke et al. 1999; McEwen 1999).

Neurogenesis in the adult brain adds one more very exciting dimension to the resilience and adaptability of the adult brain. As the three articles in this issue point out, the adult brain neurogenesis story is not a totally new one, but rather the re-opening of an old chapter, finding new meaning and new potential for a phenomenon that was largely discounted for many years. The important exception, of course, was in songbirds, where the pioneering work of Nottebohm and Arnold and their collaborators pointed very early on to the importance of adult neurogenesis in behavioral plasticity.

In mammals, the neurogenesis story lagged behind. The three articles in this issue cite the work of Joseph Altman and of M.S. Kaplan in the 1960s and 70s as having been seminal and yet largely overlooked until the studies of Elizabeth Gould and Heather Cameron focused upon the hippocampus as an important site of behaviorally-regulated neurogenesis, while the studies of Samuel Weiss, Marla Luskin and Arturo AlvarezBuylla, among others, pointed to the presence of stem cells in the subventricular zone and in other parts of the adult brain. Important work by Fred Gage, as well as by the authors of these three articles, and others who are mentioned in the articles, has shown the potential of 
stem cells to become neurons or glia depending on the local environment.

In the first of the three articles, Flora Vaccarino and colleagues describe the properties of stem cells and their ability to generate neurons and glia, including a discussion of some of the factors that guide their differentiation. Magavi and Macklis describe a fascinating story of targeted destruction of corticothalamo projection neurons that stimulates endogenous stem cells residing in the cerebral cortex to become neurons. These cells establish long-distance connections to the thalamus, a form of spontaneous brain repair. Duman and colleagues discuss the regulation of neurogenesis in the dentate gyrus from the standpoint of its potential connection to the actions of antidepressant drugs and the notion that deficits in neurogenesis may be a contributing factor in depressive illness. They also discuss the importance of second messenger pathways, particularly that involving the phosphorylation of CREB, in this process.

Besides describing progress in a dynamic and promising new field of research, the three articles raise many unanswered questions and discuss formidable obstacles, such as how useful stem cells can be in brain repair unless means can be found to stimulate the brain to more efficiently repair itself, as opposed to inserting exogenous stem cells. Another difficult challenge is evaluating whether reduced dentate gyrus neurogenesis really occurs in depressive illness. This will entail finding out how to measure neurogenesis in living human brains by imaging techniques. Furthermore, even if there is reduced neurogenesis in major depression, it is doubtful that this is the only type of structural brain change in this disorder, since reductions in glial cell number have been reported in prefrontal cortex (Rajkowska 2000) and there are indications of reduced volume in prefrontal cortex and amygdala, where neurogenesis is a rare event (Drevets et al. 1997; Sheline et al. 1998; Sheline 2000). Finally, the likelihood that limited replacement of neurons may occur in other brain regions is nevertheless very difficult to evaluate for its overall functional significance because the rate of replacement, in the absence of lesions, may be so slow as to preclude the types of studies (e.g., those of Tracy Shors and Elizabeth Gould) that have been successful in the study of the dentate gyrus.

However, these questions and technical challenges only heighten the fascination with an aspect of brain function that may provide some answers to many mysteries about the remarkable resilience and adaptability of the human nervous system.

\section{REFERENCES}

Bennett E, Diamond M, Krech D, Rosenzweig M (1964): Chemical and anatomical plasticity of brain. Science 146:610-619

Black JE, Sirevaag AM, Wallace CS, Savin MH, Greenough WT. (1989): Effects of complex experience on somatic growth and organ development in rats. Developmental Psychobiology 22:727-52

Cooke BM, Tabibnia G, Breedlove SM (1999): A brain sexual dimorphism controlled by adult circulating androgens. Proc Natl Acad Sci USA 96:7538-7540

Diamond MC, Connor Jr JR (1982): Plasticity of the aging cerebral cortex. Exp Brain Res Suppl 5:36-44

Drevets WC, Price JL, Simpson JR Jr, Todd RD, Reich T, Vannier M, Raichle ME (1997): Subgenual prefrontal cortex abnormalities in mood disorders. Nature 386:824-827

Florence SL, Taub HB, Kaas JH (1998): Large-scale sprouting of cortical connections after peripheral injury in adult macaque monkeys. Science 282:1117-21

Jones EG, Pons TP (1998): Thalamic and brainstem contributions to large-scale plasticity of primate somatosensory cortex. Science 282:1121-5

Kilgard MP, Merzenich MM (1998): Cortical map reorganization enabled by nucleus basalis activity. Science 279:1714-1718

Magarinos AM, McEwen BS, Flugge G, Fuchs E (1996): Chronic psychosocial stress causes apical dendritic atrophy of hippocampal CA3 pyramidal neurons in subordinate tree shrews. J Neurosci 16:3534-3540

McEwen BS (1999): Permanence of brain sex differences and structural plasticity of the adult brain. Proc Natl Acad Sci USA 96:7128-7130

Parnavelas J, Lynch G, Brecha N, Cotman C, Globus A (1974): Spine loss and regrowth in hippocampus following deafferentation. Nature 248:71-73

Rajkowska G (2000): Postmortem studies in mood disorders indicate altered numbers of neurons and glial cells. Biol Psychiat 48:766-777

Rand MN, Breedlove MS (1995): Androgen Alters the Dendritic Arbors of SNB Motoneurons by Acting upon Their Target Muscles. Journal of Neuroscience 15:4408-4416

Sheline YI (2000): 3D MRI studies of neuroanatomic changes in unipolar major depression: The role of stress and medical comorbidity. Biol Psychiat 48:791-800

Sheline YI, Gado MH, Price JL (1998): Amygdala core nuclei volumes are decreased in recurrent major depression. NeuroReport 9:2023-2028

Wang X, Merzenich MM, Sameshima K, Jenkins WM (1995): Remodelling of hand representation in adult cortex determined by timing of tactile stimulation. Nature 378:71-75

Yankova M, Hart SA, Woolley CS (2001): Estrogen increases synaptic connectivity between single presynaptic inputs and multiple postsynaptic CA1 pyramidal cells: A serial electron-microscopic study. Proc Natl Acad Sci USA 98:3525-3530 